\title{
Produtividade e qualidade pós-colheita de Helicônia Golden Torch submetida a fontes e doses de silício
}

\author{
Abel W. de Albuquerque 1 , José M. dos Santos² \& Alonso P. de Farias ${ }^{3}$ \\ ${ }^{1}$ CECA/UFAL. Rio Largo, AL. Fone: (82) 3261-2221. E-mail: awa.albuquerque@hotmail.com (Autor correspondente) \\ ${ }^{2}$ Instituto Federal de Alagoas. Satuba, AL. Fone: (82) 3266-1020. E-mail: j.manzil@hotmail.com \\ ${ }^{3}$ Instituto Federal de Alagoas. Satuba, AL. Fone: (82) 3266-1020. E-mail: pereirafrs@hotmail.com
}

Palavras-chave:

adubação silicatada

flores tropicais

componentes de produção

\begin{abstract}
R E S U M O
A adubação com silício pode aumentar a produtividade pelo aumento da resistência ao acamamento, ao estresse hídrico e a desidratação após a colheita. O objetivo deste trabalho foi avaliar a produtividade e a qualidade pós-colheita de Helicônia Golden Torch sob fontes e doses de silício. O delineamento experimental foi em blocos inteiramente casualizados em um esquema fatorial 3 x 4 utilizando-se três fontes de silício e quatro doses de Si. Avaliaram-se as seguintes variáveis: número de perfilhos, início de floração, comprimento da haste floral, diâmetro da haste floral, comprimento da bráctea, número de hastes florais, teor de silício nas folhas e queima da bráctea aos 5, 10 e 15 dias após a colheita. Os resultados obtidos demonstraram que a aplicação da fonte silicato de sódio foi a que melhor influenciou o crescimento da Helicônia Golden Torch. As maiores doses de silicato de sódio que influenciaram o comprimento da haste floral, o diâmetro da haste floral e o número de hastes florais foram 576, 400 e $560 \mathrm{mg} \mathrm{dm}^{-3}$. A menor queima da bráctea ocorreu quando se aplicou o silicato de sódio na dose de $550 \mathrm{mg} \mathrm{dm}^{-3}$. $\mathrm{O}$ teor de silício na folha aumentou com a aplicação de doses crescentes de silicato de cálcio.
\end{abstract}

Key words:

silicon fertilization

tropical flowers

production components

\section{Productivity and postharvest quality of Heliconia Golden Torch under different sources and doses of silicon}

\begin{abstract}
A B S T R A C T
The silicon fertilization can increase productivity by increasing resistance to lodgaing, to water stress and dehydration after harvest. The objective of this study was to evaluate productivity and postharvest quality of Heliconia Golden Torch under doses and sources of silicon. The experiment was conducted in randomized design in factorial $3 \times 4$ with four replications, utilizing three sources and four doses of silicon. The following variables were evaluated: number of tillers, the beginning of the flowering, length of flower stem, diameter of flower stem, length of bract, number of flower stem, silicon content in leaves and burning of bracts on the $5^{\text {th }}$, $10^{\text {th }}$ and $15^{\text {th }}$ day postharvest. The results showed that the application of sodium silicate was better to influence the growth of Heliconia Golden Torch. The higher doses of sodium silicate which influenced the length of flower stem, diameter of flower stem, length of bract and the number of the flower stem were 576,400 and $560 \mathrm{mg} \mathrm{dm}^{-3}$. The burning of bract was less when sodium silicate was applied at dose of $550 \mathrm{mg} \mathrm{dm}^{-3}$. Content of silicon in the leaf increased with increasing doses of application of calcium silicate.
\end{abstract}

\section{INTRODUÇÃO}

A produção de flores tropicais de corte é uma atividade que vem ganhando destaque no "agrobusiness", tornandose alternativa de investimento tanto para produtores que se utilizam de altas tecnologias como extrativistas da região amazônica que trabalham com a exploração sustentável da floresta. Para sua consolidação e expansão, o setor manifesta a crescente urgência de ações articuladas aos diferentes segmentos que fazem parte da cadeia produtiva destacando-se a necessidade da redução dos custos com insumos como os fertilizantes minerais, indispensáveis no processo produtivo e que, anualmente, representam um percentual significativo no aumento dos custos de produção (Arruda et al., 2008; Albuquerque et al., 2010).

As flores tropicais vêm sendo uma das plantas mais promissoras para a produção de flores de corte; dentro deste contexto se destacam as helicônias, principalmente por apresentarem características como beleza e rusticidade considerando-se que regiões mais distantes dos centros produtores apresentam um aumento crescente na demanda do consumo da Helicônia Golden Torch. Aliadas a isto, medidas que aumentem sua durabilidade vêm despertando o interesse dos produtores e pesquisadores (Costa et al., 2006; 2007; Torres \& Santos, 2007). Assim, a adubação com silício pode contribuir para aumentar a produtividade, sobretudo pelo aumento da sua 
resistência ao ataque de pragas e doenças e à maior resistência ao acamamento, ao estresse hídrico e à desidratação, após a colheita (Oliveira et al., 2007; Buck et al., 2008).

O silício é um dos elementos mais abundantes na crosta terrestre; entretanto, em um regime intenso de chuvas, como no caso dos trópicos, os silicatos menos resistentes liberam o silício o qual, na maioria das vezes, é rapidamente lixiviado do perfil do solo. No manejo adequado dos solos intemperizados deve-se, portanto, levar em consideração o elemento silício; no manejo desses solos é oportuno se considerar as perdas do silício por lixiviação e a exportação pelas culturas. Pesquisas no cultivo de monocotiledôneas em que foi aplicado silício constataram-se respostas de absorção e acúmulo em folhas como no caso da cultura da banana, que pertence à mesma ordem das Helicônias (Pereira et al., 2007; Souza Júnior et al., 2010).

A durabilidade pós-colheita é um dos parâmetros que devem ser considerados importantes na produção de flores para corte, visto que constitui um pré-requisito para a qualidade do produto e para o sucesso da comercialização. As flores de corte com maior concentração de carboidratos apresentam maior durabilidade pós-colheita (Castro et al., 2007). A queima da bráctea é um processo natural que ocorre com o amadurecimento, a desidratação e a senescência da inflorescência. A senescência é desencadeada sobremaneira pela síntese do etileno (conhecido como hormônio do estresse). A presença do Si diminui a perda de água reduzindo, por conseguinte, a produção de etileno (Brackmann et al., 2008; Paulino, 2012).

As escórias de siderurgia que contêm silício em suas composições químicas são um passivo para a indústria do ferro. Pesquisas nas quais se constate que sua utilidade na agricultura, tanto como corretivo de solo como fonte de silício, pode viabilizar sua utilização em escala comercial. O Brasil é o sexto maior produtor mundial de ferro-gusa com produção anual de cerca de 25 milhões de toneladas gerando, anualmente, aproximadamente 6,25 milhões de toneladas de escória (Ramos et al., 2008; Leite et al., 2008).

Objetivou-se, com este trabalho, avaliar a produtividade e a qualidade pós-colheita de Helicônia Golden Torch em diferentes fontes e doses de silício.

\section{Material e Métodos}

O experimento foi conduzido no período de julho de 2004 a julho de 2005, em condições de campo, numa área de terras pertencentes ao Instituto Federal de Alagoas - Campus Satuba, no município de Satuba, AL. A área experimental está localizada nas coordenadas geográficas: $9^{\circ} 33^{\prime} \mathrm{S}, 35^{\circ} 49^{\prime} \mathrm{W}$ e com $10 \mathrm{~m}$ de altitude. De acordo com a classificação de Köppen o clima da região foi classificado como As, ou seja, climático tropical com estação chuvosa no inverno e seca no verão.

O solo de onde foram coletadas as amostras para análise química e para o preenchimento dos vasos, foi classificado como um Argisolo Amarelo Distrófico típico a moderado, textura média argilosa (56\% de argila), relevo ondulado com declividade média de $0,05 \mathrm{~m} \mathrm{~m}^{-1}$ (EMBRAPA, 2006). Os resultados da análise química do solo se encontram na Tabela 1 . O solo utilizado para preenchimento dos vasos foi retirado da camada de $0-020 \mathrm{~m}$ sendo peneirado numa malha de $2 \mathrm{~mm}$ de abertura e misturado com os adubos orgânico, mineral e silicatado nas suas respectivas quantidades para cada vaso.

O delineamento experimental utilizado foi em blocos inteiramente casualizados em esquema fatorial $3 \times 4$ ( 3 fontes: cimento, silicato de sódio e silicato de cálcio) e 4 doses de silício $\left(0,250,500\right.$ e $\left.750 \mathrm{mg} \mathrm{dm}^{-3}\right)$ com 4 repetições. O trabalho foi conduzido de forma que os tratamentos ficaram assim definidos: $\mathrm{T}_{1}$ - $0 \mathrm{mg} \mathrm{dm}^{-3}$ de Si como cimento (CIM); $\mathrm{T}_{2}-250 \mathrm{mg} \mathrm{dm}^{-3} \mathrm{de}$ Si como cimento (CIM); $\mathrm{T}_{3}-500 \mathrm{mg} \mathrm{dm}^{-3} \mathrm{de}$ Si como cimento (CIM); $\mathrm{T}_{4}-750 \mathrm{mg} \mathrm{dm}^{-3} \mathrm{de}$ Si como cimento; $\mathrm{T}_{5}-0 \mathrm{mg} \mathrm{dm}^{-3} \mathrm{de}$ Si como silicato de cálcio (SICA); $\mathrm{T}_{6}-250 \mathrm{mg} \mathrm{dm}^{-3} \mathrm{de}$ Si como silicato de cálcio; $\mathrm{T}_{7}-500 \mathrm{mg} \mathrm{dm}^{-3}$ de Si como silicato de cálcio; $\mathrm{T}_{8}-750 \mathrm{mg} \mathrm{dm}^{-3}$ de Si como silicato de cálcio; $\mathrm{T}_{9}-0 \mathrm{mg} \mathrm{dm}^{-3}$ de Si como silicato de sódio (SINA); $\mathrm{T}_{10}-250 \mathrm{mg} \mathrm{dm}^{-3} \mathrm{de} \mathrm{Si}$ como silicato de sódio; $\mathrm{T}_{11}-500 \mathrm{mg} \mathrm{dm}^{-3} \mathrm{de} \mathrm{Si}$ como silicato de sódio e $\mathrm{T}_{12}-750 \mathrm{mg} \mathrm{dm}^{-3} \mathrm{de} \mathrm{Si}$ como silicato de sódio. Todos os tratamentos receberam esterco de gado, adubo mineral e mais a fonte de silício com suas respectivas doses.

O material propagativo foi originado de um matrizeiro do Instituto Federal de Alagoas - Campus Satuba, no município de Satuba, AL. Durante o preparo das mudas todo o material propagativo (rizoma), foi submetido a uma limpeza para remoção do solo e do excesso de raízes como medida preventiva de prováveis ataques de pragas e/ou doenças. As mudas permaneceram durante 5 min em uma solução de Benomyl e Diazinon a 0,2\% (Albuquerque et al., 2010; Farias et al., 2013).

A seleção das mudas (rizomas) teve como critério a escolha e a divisão das touceiras (matrizes) o que resultou em 300 rizomas, dentre os quais foram selecionados 200, que representaram características semelhantes em relação ao tamanho de rizoma, número de gema por rizoma e diâmetro do pseudocaule; em seguida, os rizomas foram plantados em uma sementeira tendo como substrato areia lavada (areia de rio), sendo que, após 40 dias, foram selecionadas, das 160 mudas para os sacos plásticos com $1 \mathrm{dm}^{3}$ de solo, 110 plantas destinadas para avaliações e 50 plantas para bordadura; aos 80 dias foi realizado o transplantio das plantas para vasos contendo $24 \mathrm{dm}^{3}$ de solo as quais foram transferidas para o viveiro; as plantas apresentavam, em média,

Tabela 1. Análise química de solo na profundidade 0-0,20 m antes da instalação do cultivo de Helicônia Golden Torch

\begin{tabular}{|c|c|c|c|c|c|c|c|c|c|c|c|c|c|c|c|}
\hline \multirow{2}{*}{ Prof. } & \multirow{2}{*}{$\begin{array}{c}\mathrm{pH} \\
\text { (água) }\end{array}$} & $\mathrm{Na}$ & $\mathbf{P}$ & $\mathrm{Fe}$ & $\mathrm{Cu}$ & $\mathrm{Zn}$ & Mn & \multirow{2}{*}{$\begin{array}{c}\text { MO } \\
\text { dag } \mathrm{kg}^{-1}\end{array}$} & $\mathrm{~K}$ & $\mathrm{Ca}$ & $\mathrm{Mg}$ & Al & $\mathrm{H}+\mathrm{Al}$ & CTC & \multirow{2}{*}{$\begin{array}{l}\mathbf{V} \\
\%\end{array}$} \\
\hline & & \multicolumn{6}{|c|}{$\mathrm{mg} \mathrm{dm}^{-3}$} & & \multicolumn{6}{|c|}{$\mathrm{cmol}_{\mathrm{c}} \mathrm{dm}^{-3}$} & \\
\hline $0-20$ & 6,4 & 43 & 52 & 1010 & 2,7 & 7,90 & 16,2 & 1,23 & 54 & 3,0 & 2,2 & 0,1 & 2,8 & 8,3 & 65,8 \\
\hline $20-40$ & 5,9 & 36 & 6 & 922 & 0,6 & 1,48 & 3,0 & 0,66 & 25 & 1,5 & 1,0 & 0,7 & 3,6 & 6,3 & 41,8 \\
\hline
\end{tabular}


$28 \mathrm{~cm}$ de altura, 4 folhas e 1,3 cm de diâmetro (Albuquerque et al., 2010; Farias et al., 2013).

O plantio teve como critério de seleção o vigor, a sanidade, a altura e o número de folhas por planta, sendo 40 plantas para o experimento e 32 para fins de bordadura. Todo o material foi submetido a uma limpeza para remoção de solo e raízes tratadas com uma solução contendo $1 \%$ de fungicida cúprico antes do plantio (Albuquerque et al., 2010; Farias et al., 2013).

A adubação seguiu a recomendação de Farias (2004), ou seja, no plantio foi utilizada uma mistura de adubo orgânico + mineral, cuja fonte foi o esterco de gado + NPK (05-15-05), na dose de $12 \mathrm{~L} \mathrm{e} 200 \mathrm{~g} \mathrm{~m}^{-2}$, respectivamente, em fundação. As fontes de silício utilizadas foram: O silicato de cálcio constituído de $24,2 \%$ de silício e $30,1 \%$ de cálcio, o silicato de sódio, constituído de $63 \%$ de Si e $18 \%$ de $\mathrm{Na}_{2} \mathrm{O}$ e cimento Zebu, com $15 \%$ de Si total.

Durante a avaliação do experimento não foi constatada a presença de agentes patogênicos com potencial para causar prejuízos ao desenvolvimento e à condução da cultura. $\mathrm{O}$ controle de plantas invasoras foi realizado manualmente. Com referência à presença de pragas foram registradas, nas folhas, a lagarta desfoliadora (Opsiphanes invarie), no rizoma (Castnia licus) e cochonilha da raiz (orthezia sp); apesar disto, os danos não foram significativos.

Com vista à manutenção da umidade do solo foram utilizados o sistema de irrigação com microaspersor supernet LR modelo, autocompensante e a vazão de $40 \mathrm{~L} \mathrm{~h}^{-1}$, distribuídos no espaçamento de $2,5 \mathrm{~m}$ nas linhas e $2,5 \mathrm{~m}$ nas entrelinhas. A duração da irrigação era de $2 \mathrm{~h}$ por dia resultando numa lâmina de $1,17 \mathrm{~mm}$ no vaso, assegurando uma umidade em torno da capacidade de campo; após este período a duração de irrigação passou para $4 \mathrm{~h}$ implicando numa lâmina de 2,32 $\mathrm{mm}$, mudança feita pelo aumento dos perfilhos no vaso.

Os dados de campo foram mensurados a partir do momento em que se iniciou a emissão das primeiras flores ou ponteiros, com duas colheitas semanais das inflorescências, as quais eram feitas com tesoura de poda, identificadas, acomodadas em baldes contendo água para em seguida se fazer as aferições iniciais. A colheita foi realizada entre 7 e $9 \mathrm{~h}$ da manhã nos dias em que as flores apresentavam $1 / 3$ da segunda seção (anel) da flor descoberto de acordo com Lamas (2004) apresentando, então, o ponto ideal para a colheita, ponto este de exigência do mercado em geral.

As variáveis utilizadas para avaliar os tratamentos quanto à produtividade foram: número de perfilhos emitidos por vasos - (NPV); início de floração em dias (IF); comprimento da haste floral em cm (CHF); diâmetro da haste floral em cm (DHF); comprimento da bráctea em $\mathrm{cm}(\mathrm{CB})$; número de hastes florais em unidade (NHF) e teor de silício nas folhas em dag kg-1 (TSF). As variáveis utilizadas para avaliar os tratamentos quanto à qualidade pós-colheita foram a queima da bráctea aos $5,10 \mathrm{e}$ 15 dias após a colheita em $\mathrm{mm}\left(\mathrm{QB}_{5}, \mathrm{QB}_{10}, \mathrm{QB}_{15}\right)$.

$\mathrm{O}$ número de hastes florais por metro quadrado NHF foi obtido a partir da contagem das inflorescências comercializáveis colhidas no período de avaliação; o comprimento de hastes florais CHF $(\mathrm{cm})$ foi medido com a utilização de uma fita métrica. Para a aferição do CHF a haste floral era colhida a 10 $\mathrm{cm}$ do solo e do ponto do corte até o início da inflorescência, se obtinha seu valor. $\mathrm{O}$ valor de comprimento de bráctea $\mathrm{CB}(\mathrm{cm})$ foi obtido a partir do início da inflorescência até o limite da bráctea principal, com o uso de uma fita métrica. As inflorescências eram colhidas quando atingiam o ponto de colheita com duas a três brácteas abertas de acordo com Lamas (2004).

Para mensuração da queima de bráctea aos 5,10 e 15 dias pós-colheita $(\mathrm{QBO})$, foi utilizada uma fita métrica para aferir as dimensões das brácteas (primeira bráctea de cada inflorescência) no ato da colheita e as dimensões queimadas (ressecadas) após os 5, 10 e 15 dias pós-colheita; as dimensões queimadas foram obtidas pela subtração entre os valores aferidos no ato da colheita e a parte não queimada, aos 5, $10 \mathrm{e}$ 15 dias após a colheita.

Com as dimensões foram calculadas as áreas aproximadas das brácteas pelas seguintes Eqs: 1, 2 e 3 (Paulino et al., 2013):

$$
\mathrm{A}=\frac{[(\mathrm{B}+\mathrm{b}) \mathrm{C}+3 \mathrm{CB}]}{4}
$$

em que:

$$
\begin{array}{ll}
\text { A } & \text { - área da bráctea no ato da colheita, } \mathrm{cm}^{2} \\
\text { B } & \text { - largura máxima da bráctea, } \mathrm{cm} \\
\mathrm{b} & \text { - largura da base da bráctea, } \mathrm{cm} \\
\mathrm{C} & \text { - comprimento total da bráctea, } \mathrm{cm}
\end{array}
$$

$$
\mathrm{Aq}=\mathrm{lc}
$$

em que:

Aq - área queimada da bráctea após o oitavo dia, $\mathrm{cm}^{2}$

1 - largura máxima da área queimada, $\mathrm{cm}$

c - comprimento da parte queimada da bráctea, $\mathrm{cm}$

$$
\mathrm{QBO}=\left(\frac{\mathrm{Aq}}{\mathrm{A}}\right) 100 \mathrm{c}
$$

em que:

QBO - queima da bráctea após a colheita, \%

A - área da bráctea no ato da colheita, $\mathrm{cm}^{2}$

Aq - área queimada da bráctea após a colheita, $\mathrm{cm}^{2}$

$\mathrm{O}$ teor de silício foliar (TSF) $\mathrm{mg} \mathrm{dm}^{-3}$ foi determinado de conformidade com o método da EMBRAPA (1999); para determinação do TSF foi retirado o terço médio da primeira folha de cada haste floral a partir da inflorescência, o qual foi secado em estufa a $65^{\circ} \mathrm{C}$ durante $48 \mathrm{~h}$ e só então triturado.

Os dados obtidos foram submetidos à análise de variância aplicando-se, em seguida, o teste de Tuckey (Ferreira, 2003); obtido o nível de significância das variáveis estudadas foram determinadas as equações de regressão que melhor se ajustaram em função das doses e fontes aplicadas. 


\section{Resultados e Discussão}

Através dos valores médios da Tabela 2, constatou-se que as doses e as fontes de silício para o CHF deferiram significativamente a 5\%. Para o valor médio do $\mathrm{CHF}$ a fonte SINA diferiu estatisticamente das fontes CIM e SICA. Em estudos sobre o incremento da altura da Helicônia Stricta, Machado et al. (1999) observaram que este efeito também pode estar associado a um aumento de reservas nutricionais devido ao aumento de enfolhamento das plantas. Neste sentido o silício, além de estimular o crescimento e a produtividade vegetal através do aumento da capacidade fotossintética, pode deixar as folhas mais eretas (Pereira et al., 2007; Ramos et al., 2008). Através da derivação das equações (Figura 1A) constatou-se que as doses máximas de $\mathrm{Si}$, relativas aos valores máximos do $\mathrm{CHF}$ $\left(60,2,66,7\right.$ e 58,6 cm) foram de 306,7, 576,7 e $440 \mathrm{mg} \mathrm{dm}^{-3}$, para as fontes CIM, SINA e SICA, respectivamente. Esses resultados estão de acordo com o teste de média (Tabela 2), em que a fonte SINA obteve o melhor resultado devido, provavelmente, aos

Tabela 2. Análise de variância das variáveis, comprimento da haste floral (CHF), diâmetro da haste floral (DHF), número de hastes florais (NHF) em $\mathrm{H}$. Golden Torch submetida a diferentes fontes e doses de silício

\begin{tabular}{|c|c|c|c|c|c|}
\hline \multirow{2}{*}{ Fontes } & \multicolumn{4}{|c|}{ Doses de silício $\left(\mathrm{mg} \mathrm{dm}^{-3}\right)$} & \multirow{2}{*}{ Média } \\
\hline & 0 & 250 & 500 & 750 & \\
\hline & \multicolumn{5}{|c|}{$\mathrm{CHF}(\mathrm{cm})$} \\
\hline CIM & $57,75 \mathrm{a}$ & $60,75 \mathrm{a}$ & $60,50 \mathrm{a}$ & $56,75 \mathrm{a}$ & $58,93 a$ \\
\hline SINA & $58,00 \mathrm{a}$ & $61,00 \mathrm{a}$ & $68,50 \mathrm{~b}$ & $64,00 \mathrm{a}$ & $62,87 b$ \\
\hline SICA & $58,25 \mathrm{a}$ & $56,50 \mathrm{a}$ & $60,75 a$ & $57,00 \mathrm{a}$ & $58,12 a$ \\
\hline Média & 58,00 & 59,41 & 63,25 & 59,25 & \\
\hline FV & \multicolumn{3}{|c|}{$\mathrm{GL}$} & \multicolumn{2}{|c|}{$\mathrm{QM}$} \\
\hline Fontes & \multicolumn{3}{|c|}{2} & \multicolumn{2}{|c|}{68,25 * } \\
\hline Doses & \multicolumn{3}{|c|}{3} & \multicolumn{2}{|c|}{57,38 * } \\
\hline Fontes $x$ Doses & \multicolumn{2}{|c|}{6} & & \multirow{2}{*}{\multicolumn{2}{|c|}{$19,05 \mathrm{NS}$}} \\
\hline \multirow[t]{2}{*}{ CV } & \multicolumn{2}{|c|}{6,20} & & & \\
\hline & & & $\mathrm{DHF}(\mathrm{cm})$ & & \\
\hline CIM & $0,56 \mathrm{a}$ & $0,57 \mathrm{a}$ & $0,58 \mathrm{a}$ & $0,56 \mathrm{a}$ & $0,57 \mathrm{a}$ \\
\hline SINA & $0,56 \mathrm{a}$ & $0,61 a b$ & $0,67 \mathrm{~b}$ & $0,60 a b$ & $0,61 \mathrm{ab}$ \\
\hline SICA & $0,57 \mathrm{a}$ & $0,61 \mathrm{a}$ & $0,59 a$ & $0,59 \mathrm{a}$ & $0,59 a b$ \\
\hline Média & 0,56 & 0,60 & 0,61 & 0,58 & \\
\hline $\mathrm{FV}$ & \multicolumn{3}{|c|}{$\mathrm{GL}$} & \multicolumn{2}{|c|}{ QM } \\
\hline Fontes & \multicolumn{2}{|c|}{2} & & \multicolumn{2}{|c|}{0,66 * } \\
\hline Doses & \multicolumn{2}{|c|}{3} & & \multicolumn{2}{|c|}{0,54 * } \\
\hline Fontes $x$ Doses & \multirow{2}{*}{\multicolumn{2}{|c|}{$\begin{array}{c}6 \\
6.20\end{array}$}} & & \multirow{2}{*}{\multicolumn{2}{|c|}{$0,20 \mathrm{NS}$}} \\
\hline \multirow[t]{2}{*}{ CV } & & & & & \\
\hline & & & NHF & & \\
\hline CIM & $2,25 \mathrm{a}$ & $3,00 \mathrm{a}$ & $3,00 \mathrm{a}$ & $2,00 \mathrm{a}$ & $2,56 \mathrm{a}$ \\
\hline SINA & $2,85 a$ & $5,50 \mathrm{~b}$ & $4,50 a b$ & $5,50 \mathrm{~b}$ & $4,31 b$ \\
\hline SICA & $2,55 \mathrm{a}$ & $2,00 \mathrm{a}$ & $3,75 a$ & $2,50 \mathrm{a}$ & $2,62 \mathrm{a}$ \\
\hline Média & 2,55 & 3,50 & 3,75 & 3,33 & \\
\hline FV & \multicolumn{3}{|c|}{$\mathrm{GL}$} & \multicolumn{2}{|c|}{ QM } \\
\hline Fontes & \multicolumn{2}{|c|}{2} & & \multicolumn{2}{|c|}{15,77 ** } \\
\hline Doses & \multicolumn{2}{|c|}{3} & & \multicolumn{2}{|c|}{5,16 * } \\
\hline Fontes x Doses & \multirow{2}{*}{\multicolumn{2}{|c|}{$\begin{array}{c}6 \\
45,30\end{array}$}} & & 3,2 & NS \\
\hline CV & & & & & \\
\hline
\end{tabular}

Médias seguidas da mesma letra dentro das fontes e doses, não diferem entre si (teste $\mathrm{t}$ $0,05)$. **; * - significativo a 0,01 e 0,05 de probabilidade, respectivamente, pelo teste t. NS - não significativo

CIM - Si como cimento, SICA - Si como silicato de cálcio, SINA - Si como silicato de sódio
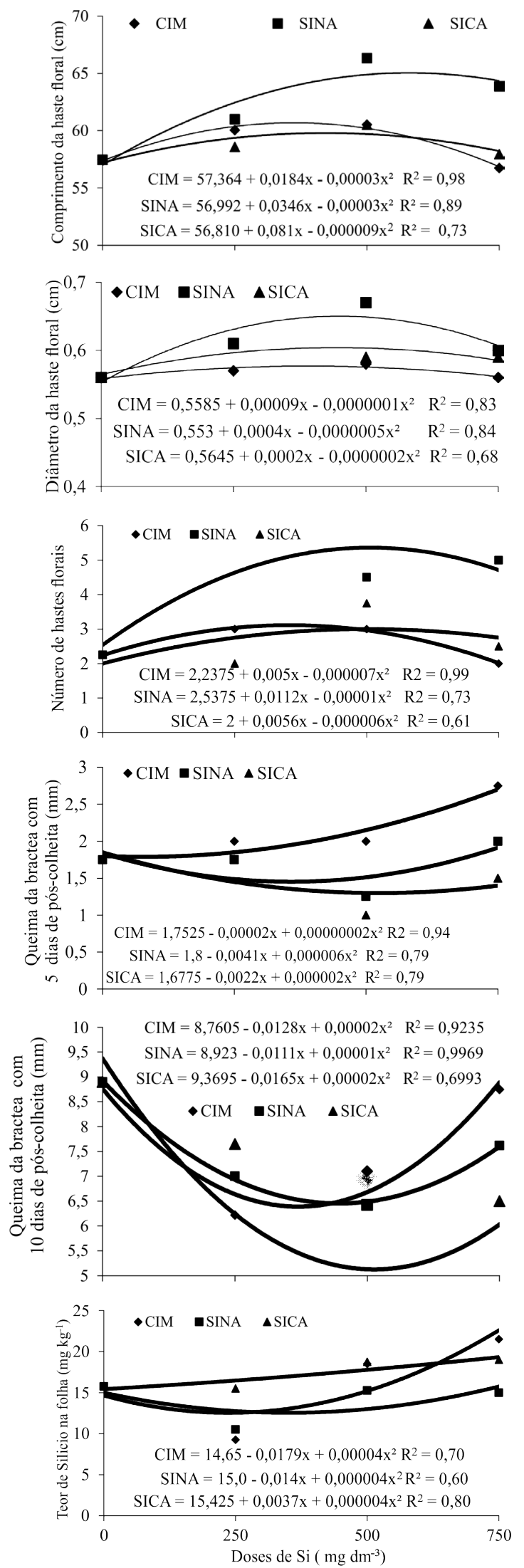

CIM - Si como cimento, SICA - Si como silicato de cálcio, SINA - Si como silicato de sódio

Figura 1. Relação entre o comprimento da haste floral, diâmetro da haste floral, número de hastes florais, queima da bráctea aos cinco e dez dias de pós-colheita, teor de Si na folha e doses de Si 
maiores teores de silício e à maior solubilidade em relação à SICA e ao CIM.

Os valores obtidos para o CHF ficaram abaixo daquele exigido pelo mercado já que se espera uma haste de cumprimento entre 70$100 \mathrm{~cm}$ (Albuquerque et al., 2010). O CHF em flores tropicais é um componente de produção importante, visto que pode influenciar diretamente a qualidade e o valor final do produto, pois com comprimentos maiores é possível fazer arranjos mais robustos com um número menor de hastes (Arruda et al., 2008). A floricultura tropical de corte tem demonstrado interesse em padronizar o tamanho da haste de flores tropicais visando ao consumidor final. Vários fatores são observados para definir o tamanho da haste, dentre os quais se destacam: a espécie e a variedade cultivada (para variedades pendentes as hastes são maiores em virtude do número de brácteas) e o tamanho da embalagem, ou seja, caixas que são padronizadas (Paulino et al., 2013).

Paulino et al. (2013) utilizando doses de silício em Helicônia Golden Torch, não constataram diferença estatística significativa para o CHF; mesmo assim, os valores obtidos oscilaram entre 78,28 e $84,74 \mathrm{~cm}$, ficando acima dos obtidos no presente estudo. Paulino et al. (2013) ressaltaram que o pequeno intervalo entre a emissão da haste floral e seu ponto de colheita aliado à lenta disponibilidade de nutrientes das fontes de silício utilizadas podem ter contribuído para que não houvesse diferença entre os tratamentos.

Apesar das variações no comprimento das brácteas (13,5 a $16,0 \mathrm{~cm}$ ), não foi observada diferença significativa. Paulino (2012) encontrou diferença significativa para o $\mathrm{CB}$ em relação às fontes de silício sendo que os valores variaram entre 17,11 e 18,93 cm e

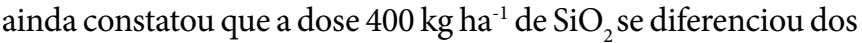
demais tratamentos contribuindo para um maior CB.

Pela análise estatística dos dados apresentados na Tabela 2 verificou-se que para o DHF houve diferença significativa a 0,05 de probabilidade para fontes e doses de silício. Para os valores máximos do $\operatorname{DHF}(0,58,0,63$ e 0,61 cm) as doses máximas de $\mathrm{Si}$ (Figura 1B) foram de 450, 400 e $500 \mathrm{mg} \mathrm{dm}^{-3}$ correspondentes às fontes CIM, SINA e SICA, respectivamente. Pode-se observar, pelo teste de médias (Tabela 2), que a fonte SINA obteve o melhor resultado em termos absolutos diferindo do tratamento com CIM.

$\mathrm{O}$ diâmetro e o comprimento da haste são dois itens que merecem atenção especial pela influência na resistência da flor em condições de campo em relação aos ventos fortes, ao transporte do campo para o local de tratamento e seleção, à embalagem e à durabilidade pós-colheita, visto que são mais rígidas (Lamas, 2004; Albuquerque et al., 2010; Farias et al., 2013). Depois de absorvido o silício é depositado nas paredes das células contribuindo substancialmente para fortalecer a estrutura da planta, aumentar a resistência ao acamamento, ao ataque de pragas e às doenças (Ramos et al., 2008). O silicato de sódio é bastante solúvel em água e por isso é recomendado para hidroponia assim como para adubação foliar; enfim, é uma alternativa para o silicato de cálcio, que é pouco solúvel em água e bem mais caro.

A análise de variância, tanto para a variável NPV quanto para a variável IF, não indicou significância para doses e fontes de silício, respectivamente (Tabela 2).
Na Tabela 2 se encontram os resultados do teste de média para a variável NHF, tendo a fonte SINA apresentado a maior média de produtividade de flores por vaso, com uma diferença de $59,1 \%$ da dose $0 \mathrm{mg} \mathrm{dm}^{-3}$ de Si (2,85 flores) para a dose 750 $\mathrm{mg} \mathrm{dm}{ }^{-3}$ de $\mathrm{Si}$ (5,5 flores). Em relação à quantidade das flores produzidas (Figura $1 \mathrm{C}$ ) as doses máximas de Si relativas às fontes CIM, SINA SICA para os maiores valores do $\operatorname{NHF}(3,13$, 5,67 e 5,1) foram de 357,560 e $500 \mathrm{mg} \mathrm{dm}^{-3}$ respectivamente. Na Tabela 2 pode-se observar que o teste de média para o NHF indica que a fonte SINA obteve o melhor resultado diferindo dos tratamentos com CIM e SICA.

As helicônias são flores tropicais de corte cuja haste floral é o produto final de importância comercial utilizada em arranjos e preparo de buquês; desta forma, para o produtor o maior número de haste floral representa menor custo de produção, maior competitividade e maior rentabilidade (Albuquerque et al., 2010; Paulino, 2012).

Referente à queima das brácteas observou-se (Tabela 3 ) que apenas as fontes apresentaram efeito significativo a 0,05 de probabilidade. Quanto menor a queima de bráctea $(1,0 \mathrm{~mm}$ na fonte SICA na dose de $500 \mathrm{mg} \mathrm{dm}^{-3}$ de Si na pós-colheita), maior será a durabilidade das flores após a colheita. As fontes, a SICA e a SINA foram estatisticamente superiores em relação à fonte CIM aos cinco dias de pós-colheita; quanto à queima da bráctea aos cinco dias de pós-colheita (QB5) observou-se (Figura 1D) que na fonte CIM a queima das brácteas aumentou enquanto nas fontes SICA e SINA ocorreu um decréscimo dos valores da queima de brácteas. Os valores máximos correspondentes a QB5 $(1,75,1,10$ e 1,67 mm), para as doses

Tabela 3. Análise de variância da variável queima da bráctea aos cinco dias (QB5) e dez dias (QB10), submetida a diferentes fontes e doses de silício

\begin{tabular}{|c|c|c|c|c|c|}
\hline \multirow{2}{*}{ Fontes } & \multicolumn{4}{|c|}{ Doses de silício $\left(\mathrm{mg} \mathrm{dm}^{-3}\right)$} & \multirow{2}{*}{ Média } \\
\hline & 0 & 250 & 500 & 750 & \\
\hline & \multicolumn{5}{|c|}{ QB5 (mm) } \\
\hline CIM & $1,75 \mathrm{a}$ & $2,00 \mathrm{a}$ & $2,00 \mathrm{a}$ & $2,25 \mathrm{a}$ & $2,12 \mathrm{~b}$ \\
\hline SINA & $1,75 \mathrm{a}$ & $1,75 \mathrm{a}$ & $1,25 \mathrm{a}$ & $1,75 \mathrm{a}$ & $1,62 a b$ \\
\hline SICA & $1,75 \mathrm{a}$ & $1,75 \mathrm{a}$ & $1,00 \mathrm{a}$ & $1,50 \mathrm{a}$ & $1,50 \mathrm{a}$ \\
\hline Média & 1,75 & 1,83 & 1,41 & 1,83 & \\
\hline FV & \multicolumn{2}{|c|}{$\mathrm{GL}$} & & \multicolumn{2}{|c|}{ QM } \\
\hline Fontes & \multicolumn{2}{|c|}{2} & & \multicolumn{2}{|c|}{2,2708 * } \\
\hline Doses & \multicolumn{2}{|c|}{3} & & \multicolumn{2}{|c|}{$0,4652 \mathrm{NS}$} \\
\hline Fontes $x$ Doses & \multicolumn{2}{|c|}{6} & & \multirow{2}{*}{\multicolumn{2}{|c|}{0,5486 NS }} \\
\hline CV & \multicolumn{2}{|c|}{45,46} & & & \\
\hline & \multicolumn{5}{|c|}{ QB10 (mm) } \\
\hline CIM & $8,75 \mathrm{a}$ & $6,25 \mathrm{a}$ & $7,25 \mathrm{a}$ & $8,75 \mathrm{a}$ & $7,75 \mathrm{a}$ \\
\hline SINA & $8,75 \mathrm{a}$ & $7,00 \mathrm{a}$ & $6,50 \mathrm{a}$ & $7,75 \mathrm{a}$ & $7,50 \mathrm{a}$ \\
\hline SICA & $8,75 \mathrm{a}$ & $7,75 \mathrm{a}$ & $3,75 b$ & $6,50 \mathrm{a}$ & $6,68 \mathrm{a}$ \\
\hline Média & 8,75 & 7,00 & 5,83 & 7,66 & \\
\hline FV & \multicolumn{3}{|c|}{$\mathrm{GL}$} & \multicolumn{2}{|c|}{ QM } \\
\hline Fontes & \multicolumn{3}{|c|}{2} & \multicolumn{2}{|c|}{ 4,93 NS } \\
\hline Doses & \multicolumn{3}{|c|}{3} & \multicolumn{2}{|c|}{17,91 * } \\
\hline $\begin{array}{l}\text { Fontes x Doses } \\
\text { CV }\end{array}$ & \multicolumn{2}{|c|}{$\begin{array}{c}6 \\
28,35\end{array}$} & & \multicolumn{2}{|c|}{$5,32 \mathrm{NS}$} \\
\hline
\end{tabular}

Médias seguidas pela mesma letra dentro das fontes e doses, não diferem entre si (teste t 0,05 ). **; *Significativo a 0.01 e 0,05 de probabilidade, respectivamente, pelo teste t. NS - Não significativo

CIM - Si como cimento, SICA - Si como silicato de cálcio, SINA - Si como silicato de sódio 
máximas de Si (CIM, SINA e SICA) foram de 500, 550 e 341 $\mathrm{mg} \mathrm{dm}{ }^{-3}$ respectivamente; através do teste de média (Tabela 3 ), pode-se constatar que a fonte SICA não diferiu do tratamento SINA (1,62 mm) mas diferiu do CIM.

Segundo Lee et al. (1990), a sílica absorvida pela planta é depositada sobretudo na parede celular aumentando a rigidez da célula e elevando os conteúdos de hemicelulose e lignina na parede, fatos esses que podem ter contribuído para a diminuição da queima das brácteas da Helicônia Golden Torch. Paulino (2012) observou, em relação aos dados obtidos, que para a queima de bráctea no oitavo dia, que não houve diferença

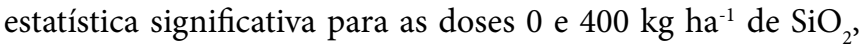
encontrando diferença estatística somente para a dose de 800 $\mathrm{kg} \mathrm{ha}^{-1}$ de $\mathrm{SiO}_{2}$.

A queima da bráctea é um processo natural que ocorre com o amadurecimento, desidratação e a senescência da inflorescência; a senescência é desencadeada sobremaneira pela síntese do etileno (conhecido como hormônio do estresse). A presença do Si diminui a perda de água reduzindo, por conseguinte, a produção de etileno (Sonego \& Brackmann, 1995; Brackmann et al., 2008). Paulino et al. (2013) também constataram que a queima de bráctea decresceu de forma linear com o aumento da dose de $\mathrm{Si}$; assim, o silício contribui para manutenção da qualidade das flores através da redução da senescência.

A perda de massa fresca se dá principalmente pela desidratação ou transpiração considerando que o Si fica depositado na epiderme dos tecidos vegetais e minimiza, assim, a saída da água. O aumento das doses de Si pode propiciar uma perda menor de massa em relação aos tratamentos sem silício (Guimarães et al., 2010; Paulino, 2012). O aumento da dose de silício diminui a perda de massa pós-colheita colaborando para manutenção da massa fresca elevando, em contrapartida, a qualidade pós-colheita das inflorescências representando, desta forma, para os produtores e comerciantes, a possibilidade de atingir mercados cada vez mais longínquos. Para Brackmann et al. (2008), Souza et al. (2009) e Guimarães et al. (2010) o uso de técnicas e de produtos que alterem a velocidade de transpiração, diminui a perda de massa pós-colheita.

Conforme a análise de variância, apenas as doses apresentaram diferença significativa a 0,05 de probabilidade. De acordo com a Tabela 3 observa-se, pelo teste de média, uma redução acentuada da queima na fonte SICA $(3,7 \mathrm{~mm}$ na dose de $500 \mathrm{mg} \mathrm{dm}^{-3} \mathrm{de} \mathrm{Si}$ ). Segundo Malavolta et al. (2002), o cálcio faz parte da parede celular cuja resistência à penetração de bactéria e fungos é assim aumentada. É provável que a combinação do cálcio mais o silício na dose de $500 \mathrm{mg} \mathrm{dm}^{-3}$ tenha contribuído para a redução da queima das brácteas.

Pela análise de regressão (Figura 1E), nota-se, nas três fontes à medida em que se aumentava a dose que se reduzia a queima decrescendo até a dose de $500 \mathrm{mg} \mathrm{dm}^{-3}$ de Si. Os valores máximos da QB10 obtidos a partir das doses máximas de Si $\left(320,555\right.$ e $\left.412 \mathrm{mg} \mathrm{dm}^{-3}\right)$ foram de 6,71, 5,84 e 5,97 mm, correspondentes às fontes CIM, SINA e SICA, respectivamente; apesar disto constatou-se, pelo teste de média (Tabela 3) que não houve diferença estatística entre as fontes.

Para a variável QB15 os resultados indicam que a durabilidade das brácteas não sofreu influência das fontes nem das doses de silício aplicadas.

Verificou-se elevação dos valores do teor de silício foliar a partir da dose de $250 \mathrm{mg} \mathrm{dm}^{-3}$ de Si em todas as fontes sendo constatada uma significância de 0,05 de probabilidade para fontes e de 0,01 para doses pela análise de variância (Tabela 4 e Figura 1F).

Tabela 4. Análise de variância do teor de silício na folha (TSF) da H. Golden Torch submetida a diferentes fontes e doses de silício

\begin{tabular}{|c|c|c|c|c|c|}
\hline \multirow{2}{*}{ Fontes } & \multicolumn{4}{|c|}{ Doses de silício $\left(\mathrm{mg} \mathrm{dm}^{-3}\right)$} & \multirow{2}{*}{ Média } \\
\hline & 0 & 250 & 500 & 750 & \\
\hline CIM & $15,75 \mathrm{a}$ & $9,25 \mathrm{a}$ & $18,50 \mathrm{~b}$ & $21,50 \mathrm{~b}$ & $16,25 \mathrm{a}$ \\
\hline SINA & $15,75 \mathrm{a}$ & $10,50 \mathrm{a}$ & $15,25 \mathrm{a}$ & $15,00 \mathrm{a}$ & $14,12 b$ \\
\hline SICA & $15,75 \mathrm{a}$ & $15,50 \mathrm{a}$ & $18,75 \mathrm{a}$ & $19,00 \mathrm{a}$ & $17,25 a$ \\
\hline Média & 15,75 & 11,75 & 17,50 & 18,50 & \\
\hline FV & \multicolumn{2}{|c|}{$\mathrm{GL}$} & & \multicolumn{2}{|c|}{ QM } \\
\hline Fontes & \multicolumn{2}{|c|}{2} & & \multicolumn{2}{|c|}{40,7500 * } \\
\hline Doses & \multicolumn{2}{|c|}{3} & & \multicolumn{2}{|c|}{106,2500 ** } \\
\hline Fontes $\mathrm{x}$ doses & \multicolumn{2}{|c|}{6} & & \multicolumn{2}{|c|}{20,4166 NS } \\
\hline CV & \multicolumn{2}{|c|}{20,10} & & & \\
\hline
\end{tabular}

Médias seguidas pela mesma letra dentro das fontes e doses, não diferem entre si (teste t 0,05$)$; ${ }^{\star *} ;{ }^{\star}$ Significativo a 0,01 e 0,05 de probabilidade, respectivamente, pelo teste $\mathrm{t}$; NS - não significativo

CIM - Si como cimento, SICA - Si como silicato de cálcio, SINA - Si como silicato de sódio

O Si na planta é pouco móvel. Devido à ausência de carga elétrica acredita-se que a absorção do $\mathrm{H}_{4} \mathrm{SiO}_{4}$ (ácido monosilícico) é de natureza não seletiva e energicamente passiva. O transporte do Si da raiz até a parte aérea se dá através do xilema e depende da taxa evapotranspirativa. Crê-se, também, que o transporte do Si se dê principalmente através do movimento ascendente da água no interior da planta (Pereira et al., 2007; Ramos et al., 2008). Depois de absorvido o ácido monossolícico é depositado especialmente nas paredes das células da epiderme contribuindo substancialmente para fortalecer a estrutura da planta e aumentar a resistência ao acamamento e ao ataque de pragas e doenças (Nolla et al., 2006).

Os resultados obtidos por Paulino (2012) para o TSF variaram entre 6,7 e 9,2 $\mathrm{g} \mathrm{kg}^{-1}$, não apresentando diferença estatística mantendo-se acima dos valores encontrados no presente trabalho $\left(0,9 \mathrm{a} 2,1 \mathrm{~g} \mathrm{~kg}^{-1}\right)$ e abaixo do intervalo descrito por Souza Júnior et al. (2010), em musáceas $\left(9,5 \mathrm{a} 10,7 \mathrm{~g} \mathrm{~kg}^{-1}\right)$. Para este autor e mesmo sendo as helicônias acumuladoras de silício, as baixas doses utilizadas não foram suficientes para diferir dos tratamentos sem $\mathrm{Si}$, uma vez que o próprio solo é uma fonte deste elemento.

Para os valores máximos do TSF $(12,64,13,95$ e 14,56 mg $\mathrm{dm}^{-3}$ ) as doses máximas de $\mathrm{Si}$ (Figura 1F) foram de 223, $462 \mathrm{e}$ $350 \mathrm{mg} \mathrm{dm}^{-3}$, correspondentes às fontes CIM, SINA e SICA, respectivamente. 


\section{Conclusões}

1. A fonte silicato de sódio foi a que melhor influenciou os componentes de produção da Helicônia Golden Torch; as maiores doses de silício que influenciaram o comprimento da haste floral, o diâmetro da haste floral e o número de hastes florais, foram de 576,400 e $560 \mathrm{mg} \mathrm{dm}^{-3}$.

2. O silicato de sódio foi a fonte que proporcionou a menor queima da bráctea quando se aplicou a dose de $550 \mathrm{mg} \mathrm{dm}^{-3}$.

3. O teor de silício na folha aumentou com a aplicação de doses crescentes de silicato de cálcio.

\section{Literatura Citada}

Albuquerque, A. W.; Rocha, E. S.; Costa, J. P. V. da; Farias, A. P.; Bastos, A. L. Produção de Helicônia Golden Torch influenciada pela adubação mineral e orgânica. Revista Brasileira de Engenharia Agrícola e Ambiental, v.14, p.10521058. 2010.

Arruda, R.; Carvalho, V. T. de; Andrade, P. C. M.; Pinto, M. G. Helicônias como alternativa econômica para comunidades amazônicas. Acta Amazônica, v.38, p.611-616, 2008.

Brackmann, A.; Eisermann, A. C.; Weber, A.; Giehl, R. F. H.; Pavanello, E. P.; Both, V. Qualidade da maçã "Gala" armazenada em atmosfera controlada associada à absorção e ao controle da síntese e da ação do etileno. Ciência Rural, v.38, p.2151-2156, 2008.

Buck, G. B.; Konrdörfer, G. H.; Nolla, A.; Coelho, L. Potassium silicate as foliar spray and rice blast control. Journal of Plant Nutrition, v.31, p.231-237, 2008.

Castro, A. C. R. de; Loges, V.; Costa, A. S. da; Castro, M. F. A. de; Aragão, F. A. S. de; Willadino, L. G. Hastes florais de helicônia sob deficiência de macronutrientes. Pesquisa Agropecuária Brasileira, v.42, p.1299-1306, 2007.

Costa, A. S. da; Loges, V.; Castro, A. C. R. de; Bezerra, G. J. S. de M.; Santos, V. F. dos. Variabilidade genética e correlações entre caracteres de cultivares e híbridos de Heliconia psittacorum. Revista Brasileira de Ciências Agrárias, v.2, p.187-192, 2007.

Costa, A. S. da; Loges, V.; Castro, A. C. R. de; Verona, A. L.; Pessoa, C. de O; Santos, V. F. dos. Perfilhamento e expansão de touceiras de helicônias. Horticultura Brasileira, v.24, p.460-463, 2006.

EMBRAPA - Empresa Brasileira de Pesquisa Agropecuária. Manual de análises químicas de solos, plantas e fertilizantes. Rio de Janeiro: Embrapa CNPS, 1999. 370p.

EMBRAPA - Empresa Brasileira de Pesquisa Agropecuária. Solos do Nordeste. Recife: UEP, Recife, PE, 2006. 8p.

Farias, A. P. Componentes de produção da Heliconia Golden Torch (Heliconia psitacorum x Heliconia spathocircinata) influenciados pela adubação mineral e orgânica. Rio Largo: UFAL, 2004. 57p. Dissertação Mestrado

Farias, A. P. Albuquerque, A. W.; Moura Filho, G.; Reis, L. S. Produtividade da Heliconia psittacorum x Heliconia pathocircinada cv. Golden Torch sob diferentes fontes de adubação orgânica. Revista Brasileira de Engenharia Agrícola e Ambiental, v.17, p.713-720. 2013.
Ferreira, D. F. Sisvar: Versão 4.2. Lavras: UFLA, 2003.

Guimarães, A. A.; Finger, F. L.; Guimarães, A. A.; Souza, P. A. de; Linhares, P. C. F. Fisiologia pós-colheita de Heliconia spp. Revista Verde de Agroecologia e Desenvolvimento Sustentável, v.5, p.38-49, 2010.

Lamas, A. da M. Flores: Produção, pós-colheita e mercado. Fortaleza: Instituto Frutal, 2004. 109p.

Lee, T. S.; Kwon, T, O; Park, K, H, Influence of nitrogen and silicon on the field and the lodging related taits of paddy rice. Soil and Fertilizers, v.32, p.15-23, 1990.

Leite, G. M. V.; Andrade L. A. B. de; Garcia, J. C.; Anjos. I. A. dos. Efeitos de fontes e doses de silicato de cálcio no rendimento agrícola e na qualidade tecnológica da canade-açúcar, cultivar SP80-1816. Ciência e Agrotecnologia, v.32, p.1120-1125, 2008.

Machado, C. F.; Graziano, T. T.; Dematê, E. S. P. Influencia do desbaste na produção de inflorescências de H. Psittacosum L. F. cv. Andrômeda. Revista Brasileira de Horticultura, v.5, p.111-119, 1999.

Malavolta, E.; Alcarde, J. C.; Gomes, P. Adubos e adubações. São Paulo: Nobel, 2002. 220p.

Nolla, A.; Korndörfer, G. H.; Coelho, L. Efficiency of calcium silicate and carbonate in soybean disease control. Journal of Plant Nutrition, v.29, p.2049-2061, 2006.

Oliveira, L. A. de; Korndörfer, G. H.; Pereira, A. N. Acumulação de silício em arroz em diferentes condições de $\mathrm{pH}$ da rizosfera. Revista Brasileira de Ciência do Solo, v.31, p.685-690, 2007.

Paulino, A. S. Cultivo de Helicônia Golden Torch sob diferentes fontes e doses de silício. Rio Largo: UFAL, 2012. 59p. Dissertação Mestrado

Paulino, A. S.; Albuquerque, A W.; Moura Filho, G.; Pereira, F. R. S. Helicônia "Golden Torch": Produtividade e qualidade póscolheita sob diferentes fontes e doses de silício. Revista Brasileira de Engenharia Agrícola e Ambiental, v.17, p.615-621. 2013.

Pereira, H. S.; Barbosa, N. C.; Carneiro, M. A. C.; Korndörfer, G. H. Avaliação de fontes e extratores de silício no solo. Pesquisa Agropecuária Brasileira, v.42, p.239-247, 2007.

Ramos, L. A.; Korndörfer, G. H.; Nolla, A. Acúmulo de silício em plantas de arroz do ecossistema de várzea submetido à aplicação de diferentes fontes. Bragantia, v.67, p.751-757, 2008.

Sonego, G.; Brackmann, A. Conservação pós-colheita de flores. Ciência Rural, v.25, p.473-479, 1995.

Souza, G. O. de,; Viégas, I. de J. M.; Frazão, D. A. C. Crescimento de Heliconia psittacorum cv. Golden Torch em função de calcário dolomítico. Revista de Ciências Agrárias, v.52, p.49-59, 2009.

Souza Júnior, S. F. de; Andrade, A. L de; Almeida, P. S. G., Marcílio, H. C.; Folman, R.; Bezerra, F. F.; Vilalba, R.; Scherer, $\mathrm{S}$. Acúmulo de silício em folhas de bananeira (Musa sp.). In: Congresso Brasileiro de Fruticultura, 20 e Annual Meeting of the Interamerican Society for Tropical Horticulture, 54, 2008, Vitória. Anais... Vitória: SBF, 2010. CD-Rom

Torres, J. S.; Santos, K. B. dos. Produção e comercialização de floricultura tropical em Teresina, PI. Resultados de pesquisas. Grupo de Estudo e Pesquisa em Floricultura Tropical (GEPFLORA), v.1, p.6-11, 2007. 